\title{
The Art of Time Travel: An 'Insoluble' Problem Solved
}

\author{
Craig Bourne $e^{1}$ and Emily Caddick Bourne ${ }^{2}$ \\ ${ }^{1}$ University of Hertfordshire \\ School of Humanities, Hatfield AL10 9AB \\ United Kingdom of Great Britain and Northern Ireland \\ c.bourne@herts.ac.uk \\ ${ }^{2}$ University of Hertfordshire \\ School of Humanities, Hatfield AL10 9AB \\ United Kingdom of Great Britain and Northern Ireland \\ e.caddick@herts.ac.uk
}

Article info

CDD: 115

Received: 30.06.2016; Accepted: 22.10.2016

DOI: http://dx.doi.org/10.1590/0100-6045.2016.V39N4.CE

\author{
Keywords: \\ McCall \\ Time travel \\ Creativity \\ Aesthetic value \\ Copying
}

\begin{abstract}
In 'An Insoluble Problem' (2010), Storrs McCall presents an argument which he takes to reveal the real problem with backwards time travel. McCall asks us to imagine a scenario in which a renowned artist produces his famous works by copying them from reproductions brought back to him by a time-travelling art critic. The novelty of the scenario lies in its introduction of aesthetic constraints on the possibility of time travel, something which sets it apart from other time travel cases. McCall states that 'The puzzle lies ... in finding where artistic creativity enters the equation', and that 'Unlike the traditional "paradoxes of time travel", this problem has no solution'. We offer four responses to McCall's puzzle. Whilst we show that the puzzle is not insoluble, we also argue that it reveals something about the proper relationship between copying and creativity, which may not have been apparent without considering time travel.
\end{abstract}

Manuscrito - Rev. Int. Fil. Campinas, v. 39, n. 4, pp. 305-313, out.-dez. 2016. 
In 'An Insoluble Problem' (2010), Storrs McCall presents a novel argument which he takes to reveal the real problem with backwards time travel. The scenario on which the argument is based makes for a subtle puzzle - and so one in danger of being overlooked - which introduces features not found in standard considerations of time travel and which warrants closer scrutiny than it has so far received. Indeed, in one of our proposed responses to McCall's puzzle, we argue that the scenario may show us something new and interesting about judgements of creativity. There is much to be gained in metaphysics and aesthetics by considering the art of time travel.

McCall's puzzle, based on an example from Dummett (1993), is this. Imagine that an art critic time-travels to the past in order to meet a renowned artist, but is disappointed to see the poor quality of what the artist has been working on. The time-travelling critic shows the artist some reproductions of the works for which he is famous. The artist then produces the works by copying from the reproductions. So long as time travel does not involve changing the past, McCall takes it to be physically possible (2010, p.647). Thus '[n]othing prevents the art critic from visiting the artist, nor the artist from copying the works that make him famous. The puzzle lies not in this, but in finding where artistic creativity enters the equation' (2010, p.647).

The problem which McCall poses seems to be that artistic creativity plays no apparent role in the existence of valued paintings. He alleges: 'What is incomprehensible is ... who or what creates the works that future generations value? Where is the artistic creativity to be found? Unlike the traditional "paradoxes of time travel", this problem has no solution' (2010, p.648).

One reading of McCall's puzzle is as follows. Given the causal processes that take place in the actual world, artworks are things which come into existence through acts of creativity. Within the causal loop described, no act of creativity takes place, which raises the question: what brings the artwork into existence? But construed in this way, as a puzzle about causal origins, the puzzle is simply a variant of a traditional paradox of time travel. The role which artworks play in McCall's story would not raise any question we could not already ask about, for instance, the plans for a time machine in a version of the information paradox in which the time traveller delivers the plans for

Manuscrito - Rev. Int. Fil. Campinas, v. 39, n. 4, pp. 305-313, out.-dez. 2016. 
her time machine to her younger self, who uses the plans to build the time machine which is used to deliver them. No act of designing the plans takes place, which raises the question: what brings the plans into existence?

This paradox requires us to disambiguate the task of explaining where the plans come from. Lewis (1976) proposes the following resolution: from within the loop, we can explain an event in terms of other events within the loop, but there may be no explanation for the loop as a whole. ${ }^{1}$ This allows us to see more clearly why McCall takes his scenario to create a novel puzzle. McCall alleges that there is no coherent way of understanding conditions which his story posits within the loop, despite the apparent possibility of a time-travel journey of this kind, and of the artist keeping and copying the reproductions. This - if McCall is correct - is because there is no way of reconciling the aesthetic value of the paintings with the way they are produced, given that 'the aesthetic value of a work of art ... lies in the artistic creativity that produces it' (2010, p.647).

We suggest that there are four responses which could be made to McCall's puzzle.

\section{Response 1: deny that the paintings have aesthetic value.}

To deny that the paintings have aesthetic value is to disagree with the aesthetic evaluations of the people in McCall's story, where '[n]o one doubts the aesthetic value of the artist's paintings' (2010, p.647). This proposed response is acceptable so long as we can explain why the art lovers would take (mistakenly) the paintings to be aesthetically valuable. And we can explain this, whilst also upholding McCall's view of where the aesthetic value of paintings lies. The paintings are judged valuable because they have features which typically result from a creative process. If they look wonderful, or there is nothing else like them, or they have inspired a new genre of painting, and so on, people will naturally be led to judge them as they would judge something similar which is produced creatively. All these features of

\footnotetext{
1 This is how the case of the artist seems to be understood by Dummett, McCall's source for the example, who notes that whilst the existence of the originals can be explained by reference to the reproductions and vice versa, there is 'no reason whatever for their joint existence' (1993, p.366).
}

Manuscrito - Rev. Int. Fil. Campinas, v. 39, n. 4, pp. 305-313, out.-der. 2016. 
the paintings would explain the conviction that people have in their positive judgement.

Of course, if McCall means by 'no one doubts' that everybody knows the paintings to be aesthetically valuable, or correctly takes them to be aesthetically valuable, then Response 1 is unavailable. But that understanding of 'no one doubts' would simply beg the question against someone who thinks the data can be accommodated without taking the paintings to be aesthetically valuable.

\section{Response 2: deny that creativity is required for the aesthetic value of paintings.}

This may be preferable to Response 1 for those who want to maintain that the paintings would have aesthetic value. To hold, with McCall, that the paintings cannot have aesthetic value without creativity in their production, one would have to maintain that where the aesthetic evaluation of paintings is concerned, all relevant features of visual appearance, art-historical significance, provocation of affect, and so on, have their aesthetic relevance only conditional on the artist's creativity. However, McCall gives us no reason to believe this contentious claim. And rejecting McCall's assumption about the connection between the aesthetic value of paintings and creativity prevents the story generating a distinctive puzzle, concerning causal loops and aesthetic value. For there is another way to read the story: an artist produced valuable paintings by copying his own reproductions, thereby becoming a counterexample to the claim that paintings get their aesthetic value by creativity. (Indeed, one might even - though this is not essential - hold that the novel way in which these paintings have been produced increases their aesthetic value.) In the absence of further argument in aesthetics, the story of the artist has no less to recommend it as a counterexample than as an insoluble problem.

Response 3: despite appearances, the scenario involves changing the past.

McCall's argument that a distinctive problem is generated by his story involves the claim that, in contrast to a story about killing one's grandmother or grandfather (before one's parent is conceived), it does not involve changing the past:

Manuscrito - Rev. Int. Fil. Campinas, v. 39, n. 4, pp. 305-313, out.-dez. 2016. 
It goes without saying that [backwards time travel] cannot, without contradiction, permit the occurrence of events that would negate the very possibility of the voyage itself. For instance, a traveller who visits the past could not kill his or her own grandmother ... However, barring such limitations, time travel is physically possible. The critic does not change the past in any way ... Nothing prevents the art critic from visiting the artist, nor the artist from copying the works that make him famous. (McCall 2010, p.647).

Despite what McCall says, however, his story does generate such a contradiction, given his assumptions about aesthetic value. Let us suppose that aesthetic value depends on creativity. Then, on the supposition that the paintings are aesthetically valuable, along with the supposition that they are not produced creatively, the scenario McCall purports to describe is contradictory: the paintings have aesthetic value in conditions which rule out their having aesthetic value. Or, putting it another way: since the paintings have aesthetic value, it is the case that they were produced creatively; but given how the artist makes them, it is not the case that they were produced creatively. Taking the critic to travel back in time with aesthetically valuable paintings smuggles in a fact about the past: that those paintings were produced creatively. To say that the artist then produces them in some other manner is to say that the past has been changed. QED. ${ }^{2}$

Given this diagnosis, the resources brought to bear when considering the standard grandfather paradox will be sufficient to deal with McCall's case. One option is to adopt Lewis's treatment (1976, pp.75-80) and say that there is a context in which it is true to say that the artist can copy his paintings from the reproductions the critic has brought, and also a context in which it is true to say that he cannot. He cannot, if we hold fixed everything else the story says, including that the paintings are aesthetically valuable, and

\footnotetext{
${ }^{2}$ Note further that the past facts in the artist case may be less noticeable than the past facts in the grandfather case, i.e. we are less aware of it being part of the story that the paintings were not produced uncreatively than we are of it being part of the grandfather story that grandfather was not killed. If so, this lends support to the view that the connection McCall takes to hold between aesthetic value and creativity is not immediately compelling (for which see Response 2).
}

Manuscrito - Rev. Int. Fil. Campinas, v. 39, n. 4, pp. 305-313, out.-dez. 2016. 
therefore not created by copying reproductions. He can, if we hold fixed a narrower collection of the facts from McCall's story, perhaps just the facts which parallel those deemed relevant to whether an artist can copy some reproductions in cases not involving time travel: the artist can see the reproductions, has a brush, canvas and the right colours of paint available, and so on. On this analysis, we can truly say, with McCall, that the critic can visit the artist and the artist can copy the works that make him famous. But it does not follow that the artist can produce aesthetically valuable works by copying. When we hold fixed only the narrow collection of facts which allows us to say the artist can copy the works, we should conclude that if the artist were to do this, then some of McCall's story would not have been true (cf. Lewis 1976, p.80). Something would have been different such that, as a matter of fact, the artist does not produce those paintings by uncreative means. For instance, perhaps the artist copies the reproductions, but it happens that somebody else had produced visually indiscernible paintings in a creative way, and these aesthetically valuable works went on to be misattributed to the artist who copies them.

This treatment of the case makes McCall's puzzle about the artist no different in kind from the grandfather paradox, and so if this is the way to solve the "traditional "paradoxes of time travel" (2010, p.648), then it should equally be taken to be a solution to the puzzle about the artist.

Of course, not everyone does think that this way of treating the grandfather paradox is a way of showing that backwards time travel is possible. Mellor (2002), for instance, argues that despite there being many coherent ways of telling some backwards time travel stories - ways in which it turns out that the time traveller happens to fail to kill her grandfather, for example - the contingency of the failure (relative to Lewis's narrower set of facts) is still problematic. For if the time traveller were to go back and attempt (even if unsuccessfully) to kill her grandfather, it would have been physically possible for her to succeed, and thereby possible for her to bring about a contradiction. Since it is not possible to bring about a contradiction, it is not possible to bring about a situation in which it is possible to bring about a contradiction. This rules out the possibility of backwards time travel in general. If this route were taken, then it would equally apply to McCall's example of the artist. The important point for our purposes is that whichever route we take concerning the possibility of backwards time travel,

Manuscrito - Rev. Int. Fil. Campinas, v. 39, n. 4, pp. 305-313, out.-dez. 2016. 
McCall's puzzle, despite his claim to the contrary, does concern changing the past and thus can be treated in the same way as the 'traditional "paradoxes of time travel".

\section{Response 4: there is no reason to say that creativity is not involved.}

McCall's story purports to describe a situation with all the following features: (1) backwards time travel takes place; (2) the artist produces his own paintings by copying them from reproductions of his own paintings; (3) the paintings are aesthetically valuable, and (4) the aesthetic value of a painting 'lies in the artistic creativity that produces it' (2010, p.647). Each of our responses so far says that these are not cotenable: Response 1 targets claim (3), Response 2 targets claim (4), and Response 3 targets (1) if we go Mellor's way and (2) if we go Lewis's way. Response 4 is different in that it shows that there is a way of satisfying all of (1)-(4). From McCall's account of what is going on in the story of the artist, we can learn something about when it is appropriate to judge an artwork to be creative, which may not have been apparent had we not considered time travel cases. Thus, even if giving a 'solution' requires something as stringent as maintaining all of (1)(4), McCall's puzzle is not insoluble.

The question on which to focus should be whether there is anything in the story which undermines the judgement that the paintings are creative, and thus the judgement that they are aesthetically valuable. Ordinarily, discovering that something is a copy makes us revise our judgement of its creativity. Copies are usually copies of some other work, and are usually made by someone other than the person who was the originator of the work they are copied from. Either of these things is (usually) a defeater of an endorsement of a work as creative. This is because the admiration we have bestowed, in judging the work to be creative, is properly directed towards something else: another work, or another artist. But in McCall's story, there are no such defeaters. The artist's paintings are all his own work, and there is no other work from which the artist's work has been copied. (After all, the paintings are copied from reproductions of themselves, not of some distinct artwork.) There is no other work or other person who we discover to be a more appropriate focus for the admiration bestowed in judging the

Manuscrito - Rev. Int. Fil. Campinas, v. 39, n. 4, pp. 305-313, out.-der. 2016. 
artist's works to be creative. Thus, there is no basis for rejecting the judgement that the works are creative.

As for the artist having been 'fifth-rate' (2010, p.647) until the time traveller's visit, that is not a defeater either. That the artist needs to see what his own finished product looks like before he can see how to produce it is a peculiarity of his method, facilitated by the peculiarities of time travel. But it has no connection to any of the features which make other cases of copying uncreative.

The pull of McCall's puzzle trades on thinking that the very act of copying renders a process uncreative. But this thought comes from certain connotations copying has, which the circumstances McCall describes require us to suspend.

What is nice about McCall's puzzle is that it introduces aesthetic constraints on the possibility of time travel, something other time travel cases do not. It also shows us something about the proper relationship between copying and creativity, which may not have been apparent without considering time travel (and this holds regardless of whether one accepts McCall's strong claim about the necessity of creativity for the aesthetic value of paintings, and indeed regardless of whether backwards causation is possible).

In McCall's introduction to a recent collection of his papers, he offers a prize for a solution to this puzzle (2014, p.7). We eagerly await our fortune.

\section{References}

DummetT, M. “Causal Loops". In R. Flood and M. Lockwood (eds.) (1986), pp. 135-69. Repr. in M. Dummett (1986), pp. 349-75.

The Seas of Language. Oxford: Oxford University Press, 1993.

Flood, R., LockwoOd, M. The Nature of Time. Oxford: Blackwell, 1986.

LEWIS, D. "The Paradoxes of Time Travel". American Philosophical Quarterly 13: 145-52. 1976. Repr. in D. Lewis (1986), pp. 67-80.

Philosophical Papers, Volume II. Oxford: Oxford University Press, 1986.

Manuscrito - Rev. Int. Fil. Campinas, v. 39, n. 4, pp. 305-313, out.-dez. 2016. 
MCCALL, S. “An Insoluble Problem”. Analysis, 70, pp. 647-48, 2010. The Consistency of Arithmetic and Other Essays. Oxford: Oxford University Press, 2014.

MeLloR, D.H. “Time Travel”. In K. Ridderbos (ed.) (2002), pp. 46-64.

Ridderbos, K. Time. Cambridge: Cambridge University Press, 2002.

Manuscrito - Rev. Int. Fil. Campinas, v. 39, n. 4, pp. 305-313, out.-dez. 2016. 